Studies in Gender and Sexuality

4(3):227-262, 2003

\title{
Tell It Slant
}

Sex, Disclosure, and HIV

\author{
Robert Klitzman, M.D. \\ Ronald Bayer, Ph.D.
}

Encounters with HIV can tell us much about how we as individuals communicate about and view our bodies and most intimate selveshow we view and approach truth, lies, sex, and trust. Better ways of handling issues of disclosure in conjunction with changed sexual practices can be crucial to thwarting the HIV pandemic. We interviewed in depth $59 \mathrm{HIV}$-infected and 18 uninfected gay, bisexual, and heterosexual men and women. Five strategies emerged for dealing with disclosure and safer sex. Clinicians and policymakers need to be as aware and sensitive as possible to the perspectives of men and women grappling with these issues.

Tell all the truth

But tell it slant, Success in circuit lies.

“ $I$ -Emily Dickinson

tell the truth about half the time," he said. Tall, handsome, and intelligent, he worked in an AIDS service agency in New

Robert Klitzman, M.D. is the Codirector of the Center for Bioethics and is an Assistant Professor of Clinical Psychiatry in the College of Physicians and Surgeons and the Mailman School of Public Health at Columbia University.

Ronald Bayer, Ph.D. is a Professor of History and Ethics of Public Health in the Department of Socio-Medical Sciences, Mailman School of Public Health at Columbia University.

227 (C) 2003 The Analytic Press 
York. His candid acknowledgment about how he spoke to sexual partners was striking and surprising. He spoke as part of a study exploring how people adapted to HIV. Other men and women as well, discussing the experience of being infected with HIV, repeatedly said that one of the hardest decisions they faced was whether to reveal the truth, to lie, or to speak in code to sexual partners and others in their lives (Klitzman, 1997).

The ability to hide information about ourselves can help us avoid unwanted intrusions from outsiders, but it also separates, isolates, and burdens us. Lies can shield those we love from painful truths, but lies also impede intimacy and friendship. How, then, do we view secrets, deceptions, and lies, and how do our views contrast with our actions?

Encounters with HIV can tell us much about how we as individuals communicate about and view our bodies and most intimate selves-how we view and approach truth, lies, sex, and trust. Sexual relationships involve an opening of the self psychologically as well as physically. Such relationships often engender expectations of trust. Husbands and wives, boyfriends and girlfriends test, probe, and adjust these expectations over time. As part of the romantic ideal, trust deepens as relationships evolve, and vice versa. But, of course, neither may be the case.

New relationships, dates, and courtships create explicit or implicit expectations and negotiations. Inevitably, judgments must be made about whether a partner can be trusted and how risky one can be in the face of uncertainty. When assumptions about a partner's candor fail, we may feel profoundly disappointed, even betrayed. Even among sexual partners who share nothing but a desire for physical pleasure some rules of interaction surely apply.

This exploration of disclosures about HIV seeks to illuminate how people integrate diagnoses into their lives and deepest notions of themselves to shape their identities. In Erving Goffman's (1963) powerful words, people must seek to "manage spoiled aspects" of their social and personal identities in a variety of contexts. They must conceal their conditions, "pass," or embrace it.

Now, 20 years after the first cases of HIV were reported, the disease continues to spread worldwide-at a rate of 16,000 new 
cases per day. Each year 40,000 new cases arise in the United States. Yet approximately one-third of the 800,000-900,000 Americans who are infected do not know it. Prevention efforts have not advanced. Recent studies have suggested that the reduced threat of HIV may have led young gay men to reduce their vigilance.

Among such men in New York City, one study found, $41 \%$ of all respondents had had unprotected anal sex during the prior six months, including $13 \%$ of those who knew themselves to be infected (Koblin et al., 2000). In San Francisco, rates of unprotected anal sex increased between 1994 and 1997, most markedly among men less than 25 years of age (Stall et al., 2000). The rates of new infection among poor African American women were even more disturbing. Among adolescents, African American females have some of the highest HIV infection rates in the United States (MMWR, 2000a). Finally, in a study conducted in six American cities (Baltimore, Dallas, Los Angeles, Miami, New York, and Seattle), 30\% of young black gay men were found to be infected with HIV. Only one third knew of their infection (Altman, 2001).

Better ways of handling issues of disclosure in conjunction with changed sexual practices are crucial to thwarting the pandemic. Such progress requires an appreciation of how those infected with HIV think about disclosing their infection and having sex. We wanted to understand how those who were infected saw their world and approached these issues of disclosure, as contrasted with those who spoke about and even for those with HIV.

Thus, we decided to interview men and women to explore how they confronted these challenges. Specifically, we decided to conduct an ethnographic study-to obtain a "thick description" (Geertz, 1973) of the world of disclosure: How do people decide whether, when, what, and to whom to disclose? Do they tell all partners or only some? And why? Do they disclose before, during, or after having sex? What, if anything, do they feel they owe their sexual partners? When they do not disclose, how do they behave sexually? What assumptions do they make about the role of truthfulness in sexual relationships? Do they make distinctions among those they view as anonymous sources of sexual gratification, those with whom they have ongoing 
relationships, and those they love? What rules and norms, if any, operate?

\section{PROTECTION OF SELF, PROTECTION OF OTHERS, AND THE AIDS PREVENTION DEBATE}

From the epidemic's outset, controversies emerged over whether infected persons had a special duty to protect their uninfected sexual partners. In the epidemic's early years, many concerned with HIV prevention rejected such claims. Those who opposed these notions raised three objections, implicitly or explicitly. The first was pragmatic; the second philosophical; the third political (Bayer, 1996).

On a pragmatic level, opponents claimed that a public health policy that focused on the responsibility of people with HIV to behave in ways that protected the uninfected would, in fact, increase the risk of HIV transmission. Those who failed to protect themselves as a result of misguided expectations that they could trust their partners would be made more vulnerable. "Patients should be cautioned that safe sex strategies are always advisable despite arguments to the contrary from partners" (Cochran and Mays, 1990, pp. 774-775).

This ethos of self-protection and "universal precautions" informed much of the AIDS prevention effort in the epidemic's first decade. Each man and woman had to be responsible for condom use. This obligation fell equally to the infected and the uninfected. As each person was responsible for his or her own health, no one was ultimately responsible for the health of the other.

A second argument against claims that the infected had a duty to protect others was philosophical. This line of reasoning sought to displace the romantic notion of "love conquers all" with suspicion derived from the commercial exchange: "Let the buyer beware." Since HIV transmission largely occurred in consensual relationships that lacked expectations of truth telling, each person bore the responsibility to protect himself or herself. Those who failed to protect themselves had no moral claim against those who had infected them (Illingworth, 1990). The possibility of the state's intruding into the most intimate 
relationships fueled this philosophical perspective; if a moral duty to protect and disclose existed, it might lead to the imposition of criminal sanctions against unsafe sex.

A final objection to the claim that those with HIV infection had special responsibilities to prevent HIV transmission was political. Threats to the privacy rights and the economic and social interests of the infected and those at risk of infection necessitated solidarity, and all efforts to distinguish between "us" and "them," the "tainted" and the "pure," those with HIV and those who had been spared had to be rejected. Dangerously divisive attempts to impose special responsibilities on the infected, it was feared, would lead to a "viral apartheid." Divisions within the communities at risk would make it more difficult to develop broad-based social support for those affected by the epidemic. Social solidarity would best be founded on the concepts of universal vulnerability to HIV and the universal importance of safer sex.

In the epidemic's first years, the ethic of self-protection rendered discussions of responsibility and self-disclosure all but impossible. The concept of self-protection had been accorded a central ideological role in the culture of AIDS-prevention efforts-especially among community-based organizations and local health departments most sensitive to the fears and concerns of those at highest risk for infection. Nevertheless, drawing on the doctrine of informed consent, some did argue that sexual partners were obligated to notify each other of their HIV status (Yeo, 1991). In an attempt to assist those who were infected to warn their sexual partners about exposure to HIV, public health departments and the U.S. Centers for Disease Control and Prevention devoted considerable attention to issues of partner notification. Nevertheless, in a 1995 review of AIDS-prevention efforts among drug users, it was noted that:

Most programs that have urged intravenous drug-users to use condoms thus far have focused on the self-protective efforts of condom use. Appealing to altruistic feelings of protecting others from HIV infection may be an untapped source of motivation for increasing condom use [Des Jarlais, Gaist, and Friedman, 1995]. 
Five years later, the Institute of Medicine (2000) would conclude that public health efforts had overemphasized the prevention of HIV acquisition by uninfected persons and had failed to recognize the critical importance of preventing HIV transmission from those who were infected: "Every new infection begins with someone who already is infected" (p. 26). Community-based organizations, recognizing the limits of the earlier focus on self-protection, were already taking up that challenge. Finally the CDC itself was compelled to acknowledge the need for change. Its own review of applications from state and city health departments for AIDS prevention funds in 1999 revealed that only one-third identified as a priority efforts at working with HIV-positive persons to reduce transmission. Thus, the federal health agency announced that it would expand prevention programs for those already infected "as a way to break the current rate of HIV transmission" (Institute of Medicine, 2000).

This evolving debate provided the context within which those we interviewed for this study had to confront their own beliefs and understandings about concealment and disclosure.

\section{Studies of Disclosure}

While not at the center of the vast social and behavioral research enterprise that has surrounded the AIDS epidemic, the issue of self-disclosure of HIV infection has nonetheless drawn attention for almost a decade. The studies, conducted in the late 1980s and early to mid-1990s, were primarily of gay men. These studies demonstrated that most infected persons revealed their infections in "primary," intimate, ongoing relationships, but not in casual or anonymous sexual relationships. For example, a study conducted by the late Samuel Perry and his colleagues (1990) in New York City showed that of gay men recently learning they were HIV positive, $90 \%$ who had past sexual partners made no attempt to inform them of the test result. Stempel, Moulton, and Moss (1995) showed in San Francisco that, after one year, a sample of gay men had informed only $56 \%$ of their new sexual partners of their status. In Los Angeles, Marks, Richardson, and Maldonado (1991) found that failure to disclose status 
occurred in conjunction with unprotected receptive and insertive anal intercourse and that self-disclosure was less likely as the number of sexual partners increased. Those who did not reveal their infections were more likely to keep it secret from partners who they believed were also infected. Finally, many of the infected gay men surveyed in these studies chose not to inform their parents and siblings. A study by Jane Simoni and her coworkers (1995) in Los Angeles lamented the extent to which investigation of disclosure until the mid 1990s had been restricted to men; those researchers found that about $90 \%$ of women revealed their HIV status to their lovers, although only half or less disclosed to family.

A few research studies, primarily quantitative, examining reasons for disclosure and nondisclosure, have found that the reasons vary according to the object of disclosure. With partners, disclosure occurred out of moral responsibility and concerns for partners' health. People disclosed to parents for support and out of a sense that these parents had a right to know. The grim prognosis associated with HIV infection made such disclosure seem especially important. People disclosed to gain support with friends as well. Nondisclosure to partners resulted from fears of rejection and the wish to maintain secrecy. Some chose not to disclose to family members, especially parents, because of feelings of shame, to avoid dependence or rejection, and to protect their families from emotional distress (Mason et al., 1995; Simoni et al., 1995).

We came to view the emerging empirical study of selfdisclosure-both its focus and its methods-as profoundly limited and limiting. We believed that a fundamentally different approach was needed-that it was crucial to provide a research context within which men and women infected with HIV could describe the ways in which they understood the moral challenges posed by disclosure to sexual partners, family members, friends, and others in their lives. We were less concerned with counting responses-how many said what to whom, the kind of approach that dominated the literature-than with providing a broad yet detailed mapping of moral, social, and psychological decisionmaking under conditions of extraordinary stress. 
In short, we wanted to paint a picture of decisions regarding disclosure rather than prepare a numerical table. Only such an approach would allow us to convey the complex, nuanced emotions of love, passion, raw lust, longing, hope, despair, and fear that powerfully shaped decisions of whether to disclose to, deceive, or trust others about HIV. We have tried to present as fully as possible the voices of our informants and have chosen to allow these men and women to speak directly. We have intruded only by imposing structure and coherence to the multiplicity of perspectives elicited in our interviews.

In all, we interviewed 77 persons, 59 of whom were infected with HIV. They were gay men, intravenous drug users, sex workers (both men and women), closeted bisexual men, and heterosexual women; many had no reason to suspect they might have been placed at risk by partners. Some were living with or married to partners who were not infected. Of the infected men, 19 were gay, 13 were heterosexual, five were bisexual. Of the infected women, 20 were heterosexual, and two were lesbians. They were Latino, African American, and Caucasian; all were New Yorkers.

Through our interviews we sought to understand the multiple dimensions of disclosure: disclosing test results, disclosing within the family or the workplace, and going public. We paid particular attention to how our subjects disclosed information about HIV in relation to sex and sexual practices. Here we present partial results of our study and focus solely on the dilemmas and strategies of disclosure and sexual practices.

\section{SEXUAL STRATEGIES}

As they faced the potential dangers of sex in the context of the AIDS epidemic-both those beyond dispute (e.g., anal intercourse without a condom) and those shrouded by uncertainty (e.g., oral sex)-men and women had to make a series of critical decisions about taking or imposing risks. How did the magnitude of risk affect those decisions? How did disclosure alter the moral issues involved when persons engaged in acts that were of clear or uncertain danger? As they struggled with these issues, both infected and uninfected subjects chose from 
among five strategies: first, disclosing HIV status and practicing safer sex; second, abstaining from sex altogether or from certain sexual acts; third, not disclosing their HIV status but adhering to safer sexual guidelines; fourth, disclosing their HIV status to partners and then engaging in unprotected sex; fifth, and most morally problematical, not disclosing their infection and engaging in unsafe sex. Typically, determinations about how to act were not once-and-for-all decisions, but shifted over time in the light of changing understandings of the epidemic, different partners, and varying contexts.

\section{"Safety"}

The very term safer-in contrast to "safe"-sex, commonly used by AIDS researchers, policy makers, and prevention specialists to describe the protective role of condoms, suggested that some degree of risk remained. Of note, the men and women with whom we spoke typically referred instead to the polar dichotomies of "safe" and "unsafe" sex. But, despite such binary characterizations, they continued to acknowledge the presence of "grey zones": lingering danger.

Even if used properly, condoms could break. They might be old. The friction of sex could tear them. Experiencing such a failure painfully taught the limits of safety. An uninfected gay social worker, Otis, thus recalled:

The irony of ironies is I don't trust condoms. A few years ago I was using condoms [from an AIDS service organization] and they broke-on proper use, too. I thought, "Even their condoms." I thought they were the most inferior quality condoms there were; I really did. And they have their name stamped on them. People put faith in that: "Oh theirs, they must be good."

Otis understood the presence of risk as necessitating disclosure.

For Sam, an infected respiratory therapist, moral concerns informed his commitment to safer sex. "I don't want the guilt of feeling it was my fault." He argued: 
I would say that it would probably be a good thing for someone to know what they're getting into, as far as the possibility of a rubber breaking or whatever. I've heard of people who double bag. There's even risk there, so I guess it boils down to: you can never eliminate all the risk. Unfortunately, it's just not a clear-cut kind of thing that you can always have one correct or incorrect answer.

The danger of a condom tear led Andrew, an infected gay artist, often to use two condoms when he and his lover had intercourse. "I don't want to take any kind of risk of a condom breaking, knowing that I'm seropositive. And even with my lover, we don't have anal sex any more or very rarely and it's always with a condom or two condoms."

Others merely accepted as unavoidable, a part of everyday life, the risks associated with such accidents. "It happened a couple of times," said Gerry, an uninfected man currently living with his infected lover, in an "open," nonmonogamous relationship. "Knowing that they can break is the risk you take. You sort of go with the flow. If it happens, it happens. What can you do afterwards? I don't panic."

And it did occur. George, a psychologist who had been tested as part of a group of apparently healthy medical professionals in San Francisco, thought he could reconstruct the timing of his infection as a result of condom failure.

I actually got infected through a condom that broke. I had tested negative, and I definitely remembered a specific event with a broken condom and having some weird kind of illness afterwards. I put it out of my mind. I just thought it was the flu or something, but in retrospect. . . . He didn't tell me he was infected. It's always a little bit easier to try to reconstruct these things, but he said some things that I started to think about afterwards.

It is unclear whether George would have acted differently had he known for certain that his partner was infected. Only in retrospect did he try to interpret his partner's coded communication. 


\section{The Question of Oral Sex}

The controversy over oral sex revealed the difficulty of choosing how to protect oneself and one's partners. Uncertainty among researchers, doctors, counselors, and public health officials fueled this debate. Clearly, abstaining from oral sex altogether was the safest course. But was it necessary to forgo the pleasure of fellatio or vaginal-oral contact entirely? At stake was not simply the ambiguity of the data. Oral sex required decisions about whether or not to make sacrifices to avoid small, perhaps negligible risks.

Some saw the absence of scientific consensus as necessitating caution. David, an uninfected teachers' union official, did not want to misstep. He noted, "If you remember in the beginning they said oral sex was still safe. They don't say that anymore, and I've heard a couple of stories now." To Henry, an uninfected, 58-year-old gay man who had never been in a long-term relationship, the tradeoffs that AIDS had imposed were clear. "I'm very conservative. I realize this is a killer virus. There was a show on TV about heart disease, and someone said that a pork chop isn't worth dying for, and he became a vegetarian. And a blow job isn't worth dying for." Although he remained uninfected, he nevertheless noted, "I realize I've lost out on a lot."

Heterosexual couples confronted the issue as well. Jane said of her relationship with her uninfected husband, "We've decided kissing and touching are okay, and we always use a condom, but we don't have oral sex anymore-that, we decided, was perhaps a little too risky." People must make judgments as to what is "too" risky. Some found the adjustment of using condoms relatively easy for vaginal or anal intercourse but unacceptable for oral sex. Audrey, an infected Ph.D. candidate, married her uninfected boyfriend after receiving her diagnosis. Of the choices she and her husband had had to make, she said, "It's just no problem with using a condom. That wasn't an issue, but oral sex was for me. I miss it, and he does, too, but not as much as I do, I don't think."

On the other hand, many gay men cited the failure of experts to reach consensus and, in the absence of definitive warnings, assumed that all oral sex was safe enough. Van, a 34-year-old 
infected gay man whose lover was uninfected, noted, "I don't think the medical community has given us much proof that it's transmitted orally." Given the data, he dismissed precautionary guidelines.

Some saw the act of categorization and the creation of lists of unsafe acts as analogous to the enumeration of sins. A history of labeling homosexual acts themselves as immoral and criminal made the state's efforts to judge sexual acts, even if in the name of public health, difficult to abide. Indeed, many viewed experts' advice with suspicion, as implicitly homophobic. Oliver, a Louisianan who looked to social class to assess trustworthiness and thus to protect himself from HIV, argued,

I don't believe all of their recommendations, especially since I've talked to one of the doctors who was in there making up the original guidelines. He told me that there were about 15 doctors and only two or three of them thought that fellatio should be in the bad category. But to be extra safe they put it there, because even two or three doctors thought it should be there. The others thought it was safe, and I know for a fact one of them does it all the time. And so do I. None of my friends have ever used condoms in sucking dick. The Canadian government's taken it off the list. I don't think our government could ever take it off the list because that would be admitting that fellatio is okay, and can you imagine those people in Washington ever admitting that?

In the face of medical uncertainty, even those less suspicious of the government perceived and welcomed community consensus that oral sex was not a significant risk. Against the backdrop of continuing medical debate, Howard, a teacher, sought to maintain this source of sexual pleasure when so much else had been judged off limits.

I think pretty much people have on the one hand settled that it's okay to have oral sex without a condom. In Philadelphia, there was a special workshop just on oral sex. They discussed nothing but oral sex for two hours, and 
there was a panel of four doctors and researchers and they couldn't come to a conclusion.

Others explicitly compared the perceived risks of oral sex to those they assumed in everyday life. Ben, a 45-year-old gay man, had occasionally denied to partners having been tested and sometimes disclosed in code or only after a delay. He said, "I don't think there's any reasonable risk, no. I mean no greater risk than walking across the fucking street." Gary, a gay man who said he "used to be Mr. Safe Sex," concurred, thinking that virtually all gay men his age were, like himself, infected. "I don't feel you need to use a condom for oral sex. I just assume everyone's positive in the gay community." Though he believed that reinfection with additional viral strains posed risks, he nonetheless had unprotected oral sex.

Even some uninfected men saw the risks as tolerable. Morris, 42 years old, for example, had been living with an infected man for a year and chose to engage in oral sex because of its erotic and psychological appeal.

I felt like the only thing I had in my life was my oral sex. It was something I wasn't going to give up entirely, because that was really the only expression I had, and although condoms can be a part of that as well, they just never really did it for me, and everything I've read told me that there was minimal risk in that activity.

But he drew a distinction between the risks of being the receptive and the insertive partner.

People go down on me; I don't go down on them. Because being unsure of their status, I couldn't rationalize the activity. There's always a chance that they're not infected. But then they might be as well. However, I guess because it's such a difficult decision to make for me, it wasn't worth the risk if I knew that they were positive.

In their willingness to engage in insertive but not receptive oral sex with men who might be infected, Morris and others distinguished between the degrees of danger in which they were 
willing to engage. Nowhere was this distinction clearer than in judging the hazards of swallowing semen. As Oscar, an uninfected gay man, said, "The thing I think is more of a threat is somebody in my ass. But most anything dealing with my mouth does not seem to be a threat, so long as I take it up to the point of ejaculation." He, like others, established limits in how far they would proceed and not swallow ejaculate. Community consensus provided the necessary imprimatur. "Practically everyone I know feels that oral sex is completely safe, but not necessarily to swallow."

But, while in the abstract it was possible to draw such distinctions, sexual passion frequently vanquished the limits established in advance. The recognition of the importance of withdrawal before orgasm conflicted with the desire to linger. As Christopher, an infected gay actor and former hustler whose partner was not infected, noted, "We ejaculate in each other's mouths once in a while and sometimes we don't. It's like you can't plan to do something. It just happens."

Even more difficult was the question of preejaculate. Those who believed that permitting a partner to ejaculate in the mouth was too risky still faced the question of "precum," which could cover the tip of the penis before orgasm. A willingness to engage in oral sex as a receptive partner without the use of condoms necessitated a determination, either implicit or explicit, that preejaculate did not represent a sufficient risk.

Given the widely understood low threat posed by preejaculate and the burden of using a condom during oral sex, some saw no alternative but to assume the risk associated with pleasure. As Craig, a hairdresser and former prostitute who had known he was infected for a decade, said,

Precum is basically a small risk. I would never perform or have oral sex performed on me with a condom on because the lubrication is disgusting. It's like sucking on a tire. Who wants that? I don't think too many people are having oral sex with condoms on, to tell you the honest to God truth. Precum is not a big issue. I guess it can also be said that it is a risk that one is willing to take. It's not like swallowing a whole load. It's like a drop as opposed to a tablespoon. 
Nevertheless, after oral sex he gargled "to help prevent disease."

Adults, he felt, had to make their own judgments about such pleasures and risks. As an infected man, he had decided that a partner's preejaculate was not sufficiently dangerous to deter him. But was he worried about those who took his penis into their mouths?

If someone's blowing me, I'm really not thinking about that. I'm thinking basically and instinctively that I'm not going to come in this person's mouth. Precum and all that stuff goes into an individual, and, just being adult, you make a decision. It's low risk. Obviously they're into doing what they're doing and they're an adult.

He felt that people competent to make an informed choice were free to take on the potential risks of low-risk sex.

Conflicts over the significance of nondisclosure could arise when sexual partners held contrasting views about the acceptability of even small risks. Maurice, an infected teacher, was sure that precum posed no risk, and he did not disclose his HIV status to a male partner.

A couple of times I have had such a strange reaction from the person that I told, that it's made me wonder whether or not it was the thing to tell right away. I was away for a month in New Mexico and had sex with a man. I did not tell him before we went to bed together that I was HIV positive. But I also didn't do anything with him or allow him to do anything with me that was in any way compromising. And then, when things got more intense between us and we started to incline toward things that would be considered marginal, I told him that I felt we had to discuss this, and he freaked out because of what I had considered to be very marginally compromising.

For him, this partner's outrage had little justification. It was a response born of ignorance.

In summary, the absence of scientific clarity led to acceptance of the risks of oral sex or the refusal to care about the hazards posed to partners. In the end, many who perceived but accepted 
the potential danger subscribed to Craig's perspective, "You take risks because you're human and you need that." Yet others continued to grapple with the larger questions about the extent of partners' moral responsibility toward each other and whether, in the face of uncertainty or even small risks, partners had a duty to disclose to ensure truly informed consent.

Not Telling and Practicing Safer Sex

Although men and women in ongoing relationships often diminished their sexual activity or adopted safer sexual practices following disclosure, those who were dating or involved in less committed relationships faced different decisions. Many "don't tell, but practice safe sex."

Claudio, a drug counselor in recovery, typified this approach, rooted in the need to protect both himself and his partners.

I didn't tell her right away, "Well I'm positive so we've got to use a condom." It was, "I'm using a condom because in case, because I haven't tested and to be protective, to protect myself and protect you." I did tell one partner. It was early on, and it gave me some kind of schooling, because I was new at this and didn't know what I should tell or not tell them. Prior to me telling her, we were very close. We had become pretty intimate, and after I told her, she disengaged. So I said okay, now I got to be careful about how I approach that. And that's the way it's been. Not that I haven't disclosed. But if it hasn't come up, I don't volunteer it. But the safer sex has been in practice. I'm being safer, and for the moment I feel they don't need to know. I have the experience of rejection, I don't want to be rejected, go through that experience.

The sting of rejection prompted him to devise his own strategy for protecting his partners.

Yet in the absence of HIV disclosure, it could be difficult to justify the use of condoms. Darryl, with a long history of imprisonment due to drug-related charges, had started to use condoms, albeit inconsistently, before his recent diagnosis of HIV because he knew that he was already at risk from drug use. 
Once discovering his infection, he was especially concerned about not transmitting his infection and about protecting himself from what he believed to be the possibility of reinfection.

With everyone that I was sexually active with from the time I started using condoms, the issue has come up, and I would say, "You know, it's part of learning to love myself a little, just like when I get into a car, loving myself is using a seatbelt, loving myself is using a condom." I'm in recovery, and that's one of the things that the 12-steps uses: learning to love ourselves. I found out that just the little things that I do show that I care about myself, and in turn show that I care about somebody else. But sometimes it don't worknot all the time.

Many gay white men in particular, even those who had had condoms break, believed that the use of condoms obviated the need for disclosure. Despite his having gotten infected as a result of condom failure, George, the psychologist, said about his anonymous partners to whom he did not disclose, "My feeling about it was always that, as long as I felt I was being safe and I didn't feel I really knew them, then I felt okay." It was the attempt to protect, even if not successful, that mattered.

In the absence of discussion, many gay men assumed the presence of HIV. In fact, when disclosure did not occur many adopted a ritual of using condoms. Christopher, the gay actor and former hustler, described how a sex partner had taken the initiative for safety without HIV being discussed. "I was having sex with a man and I was going to go for it and fuck him. And it was, 'Hey stop, we have to use a condom.' I always admired that. Yeah, that's good. Not without a rubber. I think that's good."

Deciding to practice safer sex without HIV disclosure could be based on nonverbal communication as well. Otis, the uninfected social worker, noted about such interactions:

If you can't make some kind of assessment that that person is somehow mature, reasonable, intelligent, then it's your responsibility. Maybe you shouldn't do something with that person. If you actively talk about it, maybe that would take 
your whole feeling/horniness down. Maybe you're in situations where you don't want to engage in conversations on AIDS. But if you can't get the signal that we'll have safe sex-okay, "I know that you know that I know that you know . . ."-then you have to make that decision for that person. It can be all nonverbal. If I got all those positive signals, I mean good signals, and then we go back to his place or my place and he says, "I want to fuck you without a condom," you know, wait a second, you gave me the signals.

Roger, a former drug user, put it bluntly, "It wasn't no words passed or nothing. We went to do our little thing, I pulled out the rubber and I put it on, so that was about it."

Finally, some asserted that the use of condoms-a shared responsibility of partners-carried the same moral weight as disclosure. Nancy, who had been infected by a former drugusing lover, accepted condoms as a moral alternative to disclosure. "I think they don't have an obligation to tell you. But they do have an obligation to wear a condom. I think the woman should have some condoms on her, too. It's not all a man's responsibility."

In the end, the strategy of safer sex without disclosure seemed to many appropriate, given understandings of the limits of trust, the recognition that disclosure could be difficult in sexual encounters; the belief that condoms alone could afford the ultimate form of self protection, and the view that partners had a certain degree of moral responsibility to each other. On the other hand, others saw such a strategy as inadequate to protect against transmission. While many saw the use of condoms as obviating the need for disclosure, problems could arise in that such "signs" were not always interpreted correctly, and definitions of "safe" varied. Most important, condoms could rupture.

\section{Disclosing and Having Unsafe Sex}

Other infected women and men, after explicitly disclosing their infection to their partners, engaged in unprotected sex. Frequently, such risk taking reflected a judgment that the 
potential danger mattered far less than the desire to have sex without condoms. Alternatively, unsafe sex might occur only as a "lapse"-expressing the power of underlying desires.

However much they knew about a partner's HIV infection, denial allowed people to act in potentially hazardous ways. Janet described herself as "the black sheep of the family" because she had used drugs and been a prostitute for many years. When told by her husband that he was positive, she "didn't want to believe it."

The mother of his two children died of AIDS-related cancer, and he was saying, "Well, I might have it" or something like that, but I wasn't listening. And then when I got my test results, which were negative, I would say, "Why don't you take the test?" He'd say, "No, cause you got your papers." And I assumed-that was very stupid on my part-because we were having sex, that he wouldn't have it either. Then he comes down with it. We were not using condoms. Now we do.

Because now I can actually see that he has it. Sometimes his jaw would be sunk in, or he'll have diarrhea really bad. That's when it really hit me, because even this year we had sex with no condoms, and I knew he had the virus. Twice we did, but I just don't want to believe it. I guess you'd say I was in denial.

One time the condom broke, and I said, "Did that break, Jimmy?" He said, "No, no, it didn't break." But I knew I should have said "stop" then. That was one of the times we went on and had sex without it on-you might as well say without no condom. But I knew it. I just kept on anyway. Then the other time, about a month later, we just did it with nothing. I guess we both wanted sex and we did it, but it was stupid on my part. But I had the test twice more after that. When those came out negative I said, "No more," I will carry a female condom with me now. I just can't take that chance.

Luckily, she remained uninfected. The denial made possible by asymptomatic HIV infection could be shattered by symptoms 
of full blown-AIDS, but, as we have just seen, that was not always the case.

Uninfected people might also feel that they must be "resistant" to the virus if they had not yet become infected-suggesting yet another form of denial. Karen, for example, 44 years old, thought she must have been "immune" to her partner's virus.

My boyfriend was diagnosed in 1985, but I really wasn't too familiar with it and we were still having unprotected sex. When I started in the research study in 1988 or 1989, they started taking the blood, and it came back negative the first two times. And then the next six months it started coming back inconclusive. Then I knew that I was infected. We continued to have unprotected sex.

I don't know why I thought this way, but I thought maybe because I was negative then, maybe I was doing something right. I said, "Well, I'm going to be with this man I think for the rest of my life, so maybe I don't have to, because I should have been infected a long time ago." The condom didn't feel right, he couldn't do it, or it caught us at a moment of just hot passion. So it was always, "Okay the next time, got to do it the next time." When it started coming back inconclusive, then I knew I blew it. Now we're condoming.

Others recognized that such thinking entailed rationalization. Although Ramon, a married, infected, African American former injecting drug user, ultimately concluded that he had to use condoms, he did not do so for a period of time after learning that he was positive.

I rationalized it. We've been having intercourse and sex for years and this woman is constantly negative, so the rationale is: Hey, I've been doing this for so many years, I don't have to stop doing it. I don't have to use a condom because nothing's going to happen to her, because if it's going to happen to her it should have happened to her already.

But uninfected persons permitted themselves to be placed at risk for reasons other than unwillingness to accept the fact that 
a partner might transmit HIV. To overcome the distance that HIV could create between discordant partners, some had sex without a condom. Paul wanted to feel close to his infected partner, Van, who, on occasion, urged unsafe sex, as if for one moment to banish the threat of AIDS. "A couple of nights, we didn't use protection," Paul said.

He didn't want to. He said, "Take this chance one time." But it could have been a deadly chance. I guess you could say it's luck in a way. I still feel bad because I can't feel what he's feeling, and it hurts me at times to see him suffering, and I speak with God a lot. I say what can I do? I don't know.

Like uninfected persons, HIV-positive men and women may also take risks to enhance a sense of intimacy. Emanuel, who worked as a social worker in an AIDS service organization and was committed to doing "everything right," explained,

There have been one or two times that we've not used a condom. We talked about it, and it seemed like it was more than passion, because we've had passion so many times. But it seemed like we just wanted to feel closer to each other, to have more from each other, and the condom was in the way. I felt bad, like I should have had more control, and I knew better, and she knew better. I didn't really kick myself in the ass so much for those times because I think, all things considered, for the amount of time we've been together, we've been doing pretty good. I give myself a high rating. Her, too. And it wasn't like I came in her or anything like that. I mean I know about precum and all that. I just wanted to feel that closeness. Because we've been together for six or seven years and never felt each other that way. It's always the condom. It wasn't like, if we had started that way, and then used condoms-then at least we'd have that.

Willingness of uninfected persons to have unprotected sex with infected partners could also reflect darker motivations, including self-destructive impulses and the thrill of toying with 
danger. Infected partners then had to decide whether to accede to such needs in a partner. As Christopher, the gay actor, said,

Even when I have sex with my lover now, I think, God, I love this person so much that if he's negative he could be staying negative, and I'm positive and we're having unsafe sex sometimes. We have a kind of agreement between us that's ours. It's kind of like a wedding ring: we don't care. It's not that we don't care, we just don't stop, we're just so in love with each other.

And maybe we should. It's kind of something to think about. Sometimes I really feel guilty and get this mental trip on myself by thinking: if he was ever to get sick, I would blame me. One time when me and him were first starting to get together, his best friend told me, "You should tell him to get tested and if he's negative you should break up with him." I mentioned it to Carlos, and he's like, "Knock it off. I've been doing this same thing before I met you. So it's not you. If I have AIDS, it's not because of you; it's because I've been nuts all my life." I think part of sex is that it's risky, and it's just taking that risk, like it's almost taboo, and then doing the taboo is even more mentally exciting-something that society says is wrong or is risky. So it's almost even fun. It's like a kid smoking a cigarette behind his momma's back.

It does bother me that he says knock it off. Because I just sometimes think that he has it out for himself. Sometimes I feel like we're both self-destructive. Me and him went through a drug period. Sometimes I feel this is such a selfdestructive relationship. We both want to kill ourselves, and I always thought he blamed himself for his lover's death. Like he wasn't there, and he's still punishing himself for it. And I'm blaming myself for every other little thing that can come up, like my AIDS. Him going through the whole period of putting a lover in his grave, and now knowing me. I think it scares him: like "I don't want to go through this again." When I was in the hospital two weeks ago, it was really hard for him. 
Drug use also fostered recklessness. Connie, who had been so drug involved that she was all but oblivious to her pregnancy, described how concerns about safety evaporated when she and her uninfected husband were high.

I've told him that I have the virus, but he still won't use condoms. And I told him that I'd rather him use condoms because I don't want him to get sick. But he just doesn't put them on. It hurts because I don't want him to get sick, I really don't. I love him and he's got nine kids of his own. I have one child, and altogether that's ten. Personally, I don't even enjoy sex if I'm getting high. And he knows that, so once in a blue moon he'll bother me about giving him some while he's getting high. I already told him he is going to get infected as long as he is messing with me and I'm infected. I told him point blank, "Charles, I love you. I don't want you to get sick. You know you're supposed to be using a condom. Our counselor told us that when I'm in my menstruation that's the worst time, and that's when you really should use it." He does not do it. I'm not going to sit up there and fuss with him.

Though some-particularly women, such as Connie-felt powerless to negotiate protected sex with their partners, others did not seem to be concerned that having unprotected sex could place a lover at risk. Sexual drive and passion could impel them to expose themselves or others to infection. As Neil, a closeted Southerner, said, "Sex makes people do dumb things." Eddie, an infected current crack and intravenous drug user, said:

When she first got tested she was negative, so then the only proper thing for us to do was to practice safe sex. Sometimes when you get into the heat of the sexual encounters, you don't have condoms, you forget about them. It was like a spur of the moment thing. We had no condoms, and that's when it happened, when we started doing it without it. Not only that, but I was uncomfortable with the condoms. I didn't get no feeling from it, and she wasn't 
too happy with it either. And then they're not always foolproof. It may burst on you or something like that. So we just said, Look, hey, we just be careful, and try to withdraw before coming, but you know how you get in the heat of things. Sometimes you just can't get out in time.

The worst part came when she became positive. She cried. She got very upset. She was angry so she threw a couple of things in my face: "You could have worn a condom." I said, "Yeah, well, you could have made sure I wore one." We did a little verbal whatever at each other; then after that, we calmed down.

She said, "You did this to me. I must love you a hell of a lot to stoop myself to this." Which is true, you know? I don't know if you want to call it a love thing or whatever, but she felt that she loved me more than enough, because she subjected herself to this. So I told her "I'm sorry." There wasn't much more I could do. "Forgive me." I feel bad about it. I know she'd like to punch me in my mouth about 25 times for not doing it.

But it's been five or six years, and I guess the initial shock is over now. And it's been a healthy relationship since. We are trying to practice safe sex now. We don't do it that much as we used to. Every other time we practice safe sex. We just get involved. I know this is going to sound crazy, but a lot of times we just try to do it. We leave our clothes on and we just like hump and maybe I'll come to a climax, maybe just by the friction. But then, when it starts getting too good, then what happens after that is I want to enter and then the condom is forgotten about, because who's going to run to the drawer to get a condom?

This honest, unadorned account illustrates the disjunction between sexual desire and knowing what was necessary to prevent HIV transmission-the tension between gratification and the "rules" of safer sex. Eddie's disregard for his wife's wellbeing was underscored by his understanding of a well-established scientific observation-that men can readily infect women. Thus, he went on: 
When I'm doing it, I don't give a damn. But after the fact, I think about it and I say, "Damn, we should have." But we didn't. She gets angry about it. She says, "You should have," and I says, "Yeah, I know I should have," but we didn't. So it was just a Catch 22.

Whatever his regrets, Eddie believed that there were advantages to having an infected wife. "By both of us having it, we come to better terms. We can talk easy. If she didn't have it, she might want to leave me."

Clearly, even after disclosure of HIV infection, unsafe sex may result from sexual passion, desires for physical intimacy, denial, rationalizations, self-destructive tendencies abetted by drug use, or simple disregard for a partner's well-being.

\section{Unsafe Sex Without Disclosure}

Not all the infected persons disclosed to partners before having unsafe sex. Such failures to disclose raised very different moral, social, and psychological issues than when an infected person had unsafe sex with a consenting partner who was fully aware of the risks of HIV transmission or when a person failed to disclose but engaged in "safer" sex. Unsafe sex without disclosure occurred for a variety of social, cultural, and psychological reasons. In some instances, subcultural norms made such acts acceptable. Denial about the extent to which one posed a lethal threat to others played a role, too. Finally, destructive anger or indifference to others' needs could also make such behavior possible.

Particular settings could sanction and even facilitate unprotected sex without disclosure. Setting and context, such as sex clubs and bathhouses, shaped such norms and expectations of high-risk behavior. The riskiness of encounters in these sex-charged environments could, in fact, heighten the sense of excitement. Although there is considerable dispute about the extent to which those who frequented bath houses and sex clubs used condoms, a number of the men with whom we spoke described participating in or witnessing unsafe sex. As Lance, a 52-year-old gay man who suggested that silence in 
bathhouses was an "unspoken" rule, explained, "People are not going to use safe sex in those arenas, because it's uncomfortable, and there's a certain element of risk in it that you find attractive."

Bathhouses could represent a kind of escape, permitting dangerous acts that would otherwise be unacceptable. Though he spoke of the values of 12-Step Programs and believed that self-honesty was indispensable to his own sobriety, Lance continued:

The bathhouses are kind of a sanity. You shut out the outside world, and for me especially that was true. You could live out your fantasies and in your fantasies HIV doesn't exist, and everybody's beautiful and having sex, whatever kind of sex it is that you subscribe to, and reality just doesn't sink in, unfortunately. I mean people are using safe sex at the bathhouses, but I think one of the things that has to be remembered, too, is that a lot of the people that go to the bathhouses are high, and when you're high, on whatever substance, you're less likely to take precautions. It's just immediate gratification. I think that has a lot to do with it.

In fact, with improved treatments for HIV, such behavior may have increased. As Christopher, the former hustler/actor, suggested, even though the popularity of sex clubs waned following the beginning of the HIV epidemic, they burgeoned in the mid-1990s.

There's tons of sex clubs now. I know guys that are HIV positive that go to those sex clubs three nights a week and don't use condoms or nothing like that. They go into the back room and party up. There's a big rampant sexual thing going on right now. The sex clubs and the sex and the drugs, that whole thing is happening right now, again, like the 70 s almost.

Many sought such settings to connect to others through sex, thereby depreciating the risks taken or imposed. As George, the psychologist, said eight years after his HIV diagnosis, "In 
the baths and clubs people are still engaging in unsafe sex. I think it's about the power of sex, and the need to connect."

Others rationalized as well that they had no moral responsibility toward partners willing to engage in unsafe sex. Ben, who was infected, said:

I have at various locations believed that people must be aware that many other people present were likely to be HIV carriers, infected. I assumed that if there is a million in one chance of contracting the illness by unprotected fellatio, for example, that they're there voluntarily, and I have not felt any particular moral qualms about participating to the extent of having fellatio performed, certainly without getting close to ejaculation.

He sought to temper his account by noting that he exercised some restraint by not ejaculating. He also emphasized the absence of responsibility for what occurred by stressing that his partners were free to reject what he gave. But then he went on to say:

Occasionally-this is getting into a murky area-I'll meet a partner who is into water sports, and I have pissed on someone, and it may have splashed onto their tongue. I may equate that with giving someone a carton of cigarettes for a gift. There's certainly some risk, but also there's some pleasure.

He saw his freedom to act as morally equivalent to the freedom of others to choose and to make their own risk-benefit calculations.

Questions arose as to whether such behaviors could or should be controlled in these environments. Despite efforts to reduce such practices through the use of monitors, unsafe sex could persist in these locales. Sam, a respiratory therapist, observed:

I know that they have sex police in some of these back room after-hours places, where they keep you from being unsafe. I think unfortunately it's necessary, because some people 
may drink too much and get wildly out of control. I mean it's kind of like the state's controlling your sex, but the goal here I think is to stop the infection with the virus. And if it takes them shining flashlights on people in dark rooms, then that's great.

But others, including civil libertarians, most AIDS activists, and many public health officials were skeptical about the benefit of restrictive public health measures. Craig, the hairdresser and former male prostitute, cautioned against trying to impose restrictions in such settings.

It's not the location. If a person's going to have unsafe sex, they're gonna do it behind closed doors or in a public place or a public forum. You can shut down every sex club on this island, they're still going to be in the bushes in Central Park. There are many places in the city. It's not going to stop anything by shutting down, and even the sleaziest sex clubs do provide condoms and lubrication. It is the person that chooses to go into those places. I think basically everyone is aware of the safe-sex thing and there are people that choose not to have safe sex, to blatantly swallow a load, fully aware I'm sure-unless they've been in a cave for the past few years-of what's going on.

Unsafe sex occurred not only in anonymous encounters for sexual pleasure, but also among those who exchanged sex for money or drugs. In this context, disclosure rarely occurred-it was simply not part of the commercial norm. Pam, herself infected, said that, if she disclosed to sex customers, she would lose business: "They'd say, 'See ya'." As a result, her strategy was to, "spit cum out of my mouth." By emphasizing what she did to protect herself, she clearly thought that as a sex worker she had no obligation to her clients. Those who bought sex often seemed unconcerned as well about the possibility that sex workers might be infected.

Infected clients never disclosed to sex workers and typically insisted that their sexual encounters occur without condoms. Thus, commercial sex workers were compelled to take whatever 
measures seemed appropriate or possible. While many sought to protect themselves with condoms, others took the risks necessary to get the money they needed. Beatrice, who had managed to remain uninfected, suggested the precarious struggle between danger from HIV and the need for drugs or money:

I was out there because I wanted drugs. Now, with a couple of them, I would say, "Will you use this?" And if he said no, I said well I got to look, study, see if you got any bumps, open sores. But later when it came to AIDS and I was out there, I just was too scared, because I seen so many die of this stuff, so I would say, "Well if you don't want it, somebody else will. Use this, or no." I want to get high but not my life, no. I got a little pride in me, that's why I never went too low in the gutter, 'cause I always thought a little bit more of myself than that. Yes, I was using drugs, yes, I was turning tricks. But one day I was going to stop all of this. I always looked to the future, that I was going to stop, and I got daughters. So, no, I wasn't into that.

Though she said she turned down potential clients who she thought might be infected and would not use condoms, she suggested that she might have had unsafe sex with some whose status she felt-but did not necessarily know-was negative.

Unsafe sex without disclosure occurred not only in settings defined by anonymity, cash, or drugs, where the possibility of HIV transmission was understood, but in relationships-casual as well as intimate, where assumptions varied about the presence of risk.

As described earlier, the heat of passion could lead to unsafe sex without disclosure even between persons in relationships who thought they might be infected. Darryl, for example, who had spent years in jail on drug charges and was committed to recovering, used condoms before his diagnosis but nevertheless placed his girlfriend at risk. "What went through my head was, damn, just suppose I am infected. I'd be putting her at risk. But I guess in the heat of passion-a lot of time it overrides intellectual thinking." 
Others knew they were positive but engaged in unsafe sex without disclosure. Some did so assuming that no additional risk existed for them and that their partners were in all likelihood already infected. Gary, who "used to be Mr. Safe Sex," said:

I never left home without my rubbers. These days, I think I'm joining a majority of positive people who, when you're with somebody positive it's like, "What, are you going to catch something?" I know you can logically. But it's nice to have sex without a condom and not be worried. It's just more intimate. So that's where I'm at right now. Occasionally I use them, but not that much.

When asked if he had had sex with anyone who was negative, he responded "No. I never run into people that are negative."

Rationalizations, even self-acknowledged, could abet such risky behavior, underplaying the dangers involved. Patrick, a closeted bisexual police officer, ultimately took two years to tell the woman he loved and would marry. In that period he continued to have unprotected sex with her. He also did not disclose to casual sexual partners with whom he had unprotected intercourse, although he withdrew before ejaculation.

There were three women, prior to my wife, that were onenight stands. I can remember thinking that as long as I don't come in them-and now I know that's totally fucking false-but my thinking was well just don't come in them. I always pulled out toward the end. I thought about it, but there was a lot of lust driving me toward just having sex. There was concern but there wasn't enough at that time to make me stop, or think of using a condom, because I just didn't. Now I carry contraceptives, but then it was not a thing.

Moral awareness thus was a poor mechanism for controlling sexual desire.

Indifference to the health of others-an indifference due in part to drugs-could also lead to nondisclosure and unsafe sex. Though adopting more responsible behavior in recent years, 
Dolores, who, like Janet, referred to herself as the "black sheep" in her family, described how while hustling in the street she had ignored the risks she could pose to partners who were not customers.

I probably slept with people and didn't tell them neither, because at that time I didn't care. Now it's a whole new thing for me. It's something I did to myself, nobody did this to me. Why make somebody else's life miserable because I did something to me? But back then, if I weren't married and had a partner to sleep with every day at my own house, I probably would sleep with anybody-didn't make no difference. I was drugging, too.

Much of the AIDS-prevention effort has, for obvious reasons of public health, emphasized the importance of practicing safer sex and using condoms. Indeed, these efforts have prioritized safer sex over disclosure. Yet here we have discovered how, for a variety of reasons having to do with intimacy, the courting of danger, and the desire to bear children, even after disclosure some persons elected to eschew condoms. Such choices were made both by infected men and women who could transmit HIV and by uninfected persons who could place themselves at risk. No understanding of the dynamics of living with HIV would be complete without an appreciation of how and why such decisions were made.

Finally, as we saw in the discussion of hidden dangers, others chose to engage in unsafe sex without disclosure. Those who encountered such people in venues known to be hazardous could choose to protect themselves. In other instances, trust or naiveté made condoms seem unnecessary. Such circumstances imposed dangers. The only "protection" was the fact that exposure did not always result in transmission.

\section{DISCUSSION}

We began our inquiry exploring such morally freighted terms as secrets, lies, concealment, and candor. By listening to women 
and men infected with HIV or living in the shadow of risk, we have come to appreciate more deeply the complexities of truth telling in every-day life.

In the case of HIV, the nature of the secret is itself vital. Secret keeping-confidentiality-offered by many HIV clinical settings and agencies facilitates testing, treatment, and psychological support. Concealment may protect both the infected persons and those for whom they care or may injure and thus impose unanticipated risks.

Again and again through these accounts, we have been struck by the difficulty of choices people had to face under conditions of uncertainty. The uninfected had to make troubling assessments of whether or not to believe what they were told by their sexual partners. Communication about HIV was itself often ambiguous, filled with cues and clues that an infected partner might believe passed for disclosure. To act on trust might expose one to a lethal virus, but to choose not to accept the word of a partner could impair the growth of a relationship. Even when uninfected persons decided to act self-protectively until they established a foundation of trust, agonizing questions remained about when that moment had come. Some felt it never arrived. Almost all wrestled with the quandary that social life required some degree of trust-the faith that those we let into our lives will not hurt us-despite the lingering possibility of danger.

Infected men and women had to act in the face of ambiguity, choosing over time between the benefits of concealment-of "passing" in Erving Goffman's (1963) term-and those of disclosure. They had to weigh the need to share their secrets with parents, children, siblings, friends, and others who might provide love and support, against the risk of burdening others and being rejected or betrayed. They sought guides but found little certainty. The most difficult moral choices lay in decisions about whether or not to disclose to sexual partners. These choices had to be made against backdrops of shifting definitions and understandings of what constituted risk. Disclosure could lead to painful rejection and end relationships that provided erotic pleasure and economic and emotional security. On the other hand, failing to tell the truth could represent a deception, 
a betrayal of trust that could be lethal, depending on the riskiness of the sexual behavior involved.

These intensely personal considerations have set the stage for policies intended to confront the HIV epidemic. In addressing these matters, policy makers have drawn on their own ideologies regarding the importance of privacy, public health, and safety and the role of coercive measures in fighting epidemics. But they have also had to rely on their own understandings of the worlds of people with or at risk of HIV infection. Some who formulated policy acted in the face of total ignorance. Others at times sensitively balanced public health with the fears and needs of these individuals.

The world of policymakers contrasts sharply with that of persons infected with HIV. The latter struggle daily with burdens of illness and the dilemmas of whether and how to tell others about their medical condition. Policymakers operate in the public arena; persons with HIV, in a private, intimate, often secretive one. The policy makers' universe is filled with abstract "populations." People with HIV live in a world of husbands, wives, lovers, sexual partners, friends, and family members who may expect information. Interpersonal dynamics are shifted and tangled.

To be effective, policy makers, as much as possible, need to be aware of and sensitive to the views and perspectives of the men and women described here. To limit the spread of HIV infection and encourage disclosure and protective sexual behavior, public efforts must appreciate the diversity of cultures in which the epidemic has been seeded. The norms and expectations of heterosexual marriage differ markedly from those of courtship and dating. The mores and expectations within gay communities vary even more dramatically. Thus, while the goals of public health policy may be singular-to prevent the spread of HIV-intervention strategies may require exquisite sensitivity and flexibility.

When policy makers have been insensitive to the fears, concerns, and needs of those infected with HIV, the result has been neglect or punitive actions that failed to protect the public health. Owing in large part to the extraordinary efforts of activists-many of whom were infected-and their allies, both 
inside and outside the government, AIDS policy in America has in general avoided the pitfalls of a mindless embrace of coercion.

In the end, a consensus emerged that safeguarding people with HIV against discrimination and providing access to medical care would do much to protect the nation's health and counter the stigma that prompts fears of disclosure. But stigmatization also arose from cultural forces strongly resistant to changelatent and manifest homophobia, racism, and fear of and revulsion toward intravenous drug use. As a consequence, despite gradually increasing visibility, and in many quarters acceptance of HIV since the 1980s, numerous infected persons still feel that they have no choice but to hide their diagnosis. Facilitating appropriate self-disclosure, with its personal and public health benefits, will require ongoing efforts to confront the cultural and social factors that underlie such animosity.

This analysis can also serve as a case study for exploring the role of multidisciplinary methods of ethnography and narrative in other areas of psychology and medicine, such as disclosures of other taboo disorders-including sexually transmitted and genetic diseases that can be given to others-as well as mental illness.

We have raised more questions than we have answered, but illuminating the multifacetedness of these issues is part of our intent. In so doing we have been guided by the assumption that understanding these dilemmas is more crucial to their ultimate resolution than proffering simple and premature answers. In a world where the escalating rates of HIV infection threaten the lives of millions, where stigma, silence, and poverty hobble efforts at even rudimentary prevention, the complexities of the accounts presented here may provide some insights into the challenges that lie ahead.

Americans are at once both increasingly anxious about unwarranted intrusions on privacy and seduced by a confessional culture. In this milieu, the narratives of men and women with HIV infection can serve as lasting reminders of the vitality and fragility of encounters with disease; and of the necessary but impossible challenges of building trust and communicating with each other in an uncertain world. 


\section{REFERENCES}

Altman, L. K. (2001), Study in 6 cities finds HIV in $30 \%$ of young black gays. The New York Times, Feb. 6, p. A17.

Bayer, R. (1996), AIDS prevention-Sexual ethics and responsibility. New Eng. J. Med., 334:1540-1542.

Cochran, S. \& Mays, V. (1990), Sex, lies, and HIV. New Eng. J. Med., 322:774-775.

Des Jarlais, D., Gaist, P. \& Friedman, S. (1995), Sci. Eng. Ethics, 1:133-144.

Geertz, C. (1973), Interpretation of Culture. New York: Basic Books.

Goffman, E. (1963), Stigma: Notes on the Management of Spoiled Identity. Englewood Cliffs, NJ: Prentice-Hall.

Illingworth, P. (1990), AIDS and the Good Society. London: Routledge.

Institute of Medicine (2000), No Time to Lose. Washington, DC: National Academy Press.

Klitzman, R. (1997), Being Positive: The Lives of Men and Women with $H I V$. Chicago, IL: Ivan R. Dee.

Koblin, B., Torian, L., Guilin, V., Ren, L., Mackeller D. \& Valleroy, L. (2000), High prevalence of HIV infection among young men who have sex with men in New York City. AIDS, 14:1793-1800.

Marks, G., Richardson, J. \& Maldonado, N. (1991), Self-disclosure of HIV infection to sexual partners. Amer. J. Pub. Health, 81:1321-1322.

Mason, H., Marks, G., Simoni, J., Ruiz, M. \& Richardson, J. (1995), Culturally sanctioned secrets? Latino men's nondisclosure of HIV infection to family, friends, and lovers. Health Psychol., 14:6-12.

MMWR (2000a), Cluster of HIV-infected adolescents and young adultsMississippi, 1999. Morbidity E Mortality Weekly Report, 49:861-864. (2000b), HIV-related knowledge and stigma-United States, 2000. Morbidity E Mortality Weekly Report, 45:1062-1064.

Perry, S., Ryan, J., Fogel, K., Fishman, B. \& Jacobsberg, L. (1990), Voluntarily informing others of positive HIV test results: Patterns of notification by infected gay men. Hosp. Community Psychiat., 41:549-551.

Simoni, J., Mason, H., Marks, G., Ruiz, M., Reed, D. \& Richardson, D. (1995), Women's self-disclosure of HIV infection: Rates, reasons, and reactions. J Consult. Clin. Psychol., 63:474-478.

Stall, R., Hays, R., Waldo, C., Ekstrand, M. \& McFarland, W. (2000), The gay 90s: A review of research in the 1990s on sexual behavior and HIV risk among men who have sex with men. AIDS, 14 (suppl. 3):101-S114.

Stempel, R., Moulton, J. \& Moss, A. (1995), Self-disclosure of HIV-1 antibody test results: The San Francisco General Hospital Cohort. AIDS Educ. EO Prevent., 7:116-123. 
Yeo, M. (1991), Sexual ethics and AIDS: A liberal view. In: Perspectives on AIDS: Ethical and Social Issues, ed. C. Overall \& W.P. Zion. Toronto: Oxford University Press, pp. 75-90.

Robert Klitzman, M.D.

HIV Center for Clinical and Behavioral Studies

NYS Psychiatric Institute, Unit 15

New York, NY 10032

rlk2@columbia.edu

Ronald Bayer, Ph.D.

722 West 168th Street

Mailman School of Public Health

Columbia University

Center for the History E Ethics of Public Health, 9th Floor

New York, NY 10032

Rb8@columbia.edu 
Copyright $\odot 2003$ EBSCO Publishing 